\title{
SMALL VIRUS PARTICLES IN FAECES OF PATIENTS WITH INFECTIOUS HEPATITIS (HEPATITIS A)
}

\author{
Susan J. Skidmore and Elizabeth H. Boxall \\ Regional Virus Laboratory, East Birmingham Hospital, Birmingham B9 5ST
}

Plates III-VII

By the technique of immune electronmicroscopy (IEM), Feinstone, Kapikian and Purcell (1973) and Feinstone et al. (1974) found a 27-nm particle with a density of 1.4 in acute-phase stools from volunteers infected with the MS-1 strain of infectious-hepatitis agent (Krugman et al., 1959). They suggested that this might be a parvovirus.

Provost et al. (1973) infected marmosets with serum or plasma from infectious-hepatitis patients and then recovered from the marmosets' sera particles which, although $27 \mathrm{~nm}$ in diameter, had a density of 1.34. Further studies showed that the infectivity of the patients' serum for marmosets was neutralised by anti-MS-1 serum. The size of the particle, its intracytoplasmic location in liver cells, resistance to ether, acid and heating to $60^{\circ} \mathrm{C}$ and its susceptibility to formalin, ultraviolet light and heating to $100^{\circ} \mathrm{C}$ suggested to Provost et al. (1975) that this might be an enterovirus.

Leger et al. (1975) and Gravelle et al. (1975), investigating an outbreak of infectious hepatitis in Phoenix, USA, also found 27-nm particles associated with the illness. Virus from this source was infectious for chimpanzees, and particles from both human and chimpanzee stools were found to have a density of 1.32-1.33 (Bradley et al., 1975).

We describe similar particles of peak buoyant density $1.34-1.35$ found in stools from infectious-hepatitis patients and their contacts. These particles had a size range of $21-28 \mathrm{~nm}$ with a peak at 23-24 nm. At first we used the technique of IEM as described by Feinstone et al. (1973) to detect particles in faeces, but later found that the particles could be extracted more easily from faeces by centrifugation in a caesium-chloride gradient. Fractions from gradients could be prepared for either direct electronmicroscopy or IEM after dialysis. The particles found were agglutinated by an anti-MS-1 serum; this suggested that they are antigenically related to particles described in America.

\section{MATERIALS AND METHODS}

Samples of faeces and serum were obtained from East Birmingham Hospital, Birmingham Public Health Department and New Central Hospital, Inverness, Scotland.

Phages designated. $\mathrm{Q} \beta, \mathrm{R} 17$ and $\Phi \times 174$ were obtained from the Department of Virology, Birmingham University.

Received 15 May 1976; accepted 7 July 1976.

J. MED. MICROBIOL.--VOL. 10 (1977) 
Preparation of faecal material. Suspensions of faeces, about $15 \%(\mathrm{v} / \mathrm{v})$ in phosphatebuffered saline (PBS), were first centrifuged in an MSE Superminor at 3000 r.p.m. $(2500 \mathrm{~g})$ for $10 \mathrm{~min}$. The supernate was centrifuged in a Spinco 40 angle-head rotor at 7000 r.p.m. $(4000 \mathrm{~g})$ for $30 \mathrm{~min}$. to deposit cellular debris and bacteria. The supernate, after the second centrifugation, was used in IEM studies, but for buoyant-density determinations, concentrated suspensions were used. For these, $40 \mathrm{ml}$ of suspension was centrifuged at 50000 r.p.m. $(200000 \mathrm{~g}$ ) in an MSE 60 angle-head rotor for $2 \mathrm{~h}$. The pellet was resuspended in $1 \mathrm{ml}$ of PBS to give a 40 -fold concentration.

Immune electronmicroscopy. This was performed by mixing $0.5 \mathrm{ml}$ of clarified faecal suspension with $0.1 \mathrm{ml}$ of serum (neat or after dilution in PBS). After incubation at $4^{\circ} \mathrm{C}$ for $18 \mathrm{~h}$., the volume was made up to $5 \mathrm{ml}$ with PBS and centrifuged at 15000 r.p.m. $(20000 \mathrm{~g})$ for $30 \mathrm{~min}$., in an MSE 50 swing-out rotor. The pellet was resuspended in a drop of distilled water and prepared for electronmicroscopy as described below.

Caesium-chloride density centrifugation. A 1-ml volume of concentrated faecal sample was layered on to $4 \mathrm{ml}$ of caesium chloride, density $1.4(0.625 \mathrm{~g}$ per ml). The gradient was centrifuged at $4^{\circ} \mathrm{C}$ for $18 \mathrm{~h}$ at 40000 r.p.m. $(150000 \mathrm{~g})$ in an MSE 50 swing-out rotor. Fractions, each of $0.2 \mathrm{ml}$, were collected from the bottom of the tube and the refractive index of each fraction was measured.

Electronmicroscopy. Grids covered with formvar membranes were dipped into the suspension and allowed almost to dry. They were then washed three times in distilled water, mopped with filter paper between each wash, and finally dipped into potassium phosphotungstate stain, $2 \% \mathrm{w} / \mathrm{v}, \mathrm{pH} 5 \cdot 5$. When dry, they were examined in a Philips EM200 electron microscope, the magnification of which had been calibrated by means of beef-liver catalase.

\section{RESULTS \\ Immune electronmicroscopy}

The following suspected cases of infectious hepatitis and their contacts were studied: (1) three isolated cases in the Birmingham area; (2) three cases in one family; (3) 29 persons (22 cases and 7 contacts) in an outbreak in the Castle Vale area of Birmingham; and (4) six cases from Inverness. Of these, 16 gave positive results by IEM, although in most instances only one or two clumps of 23-24-nm particles were detected per grid. These tests were performed with homologous convalescent serum, when this was available, or with heterologous convalescent serum; paired sera were not obtained.

Particles from patient J. McG. (an isolated case) were agglutinated by his own serum (fig. 1a) and by the convalescent serum of patient R. L. (one of the family outbreak) (fig. 1b). This serum also agglutinated particles found in faeces from R. L. and those found in the faeces of his father (J. L.).

The large outbreak of infectious hepatitis in the Castle Vale area presented an excellent opportunity to obtain large numbers of samples. However, most of them were collected after the time of expected maximum shedding of antigen, and in only four of 22 patients could particles be found by IEM (figs. $2 a$ and $2 b$ ). Most of the remaining samples were collected 20-48 days after the onset of illness and would have been expected to contain little or no virus. To overcome the difficulty of obtaining acute-phase samples, arrangements were made for the collection of faecal samples from contacts weekly for up to 4 weeks or longer if infectious hepatitis developed. Although none of the contacts showed symptoms of hepatitis A, antigen was found in two samples; in both cases it was agglutinated by the convalescent serum of their infected contact (fig. 3). 
Of six samples sent to us from Inverness, five were found to contain viruslike particles of similar size to those found elsewhere (figs. $4 a$ and $4 b$ ). IEM.

Twenty control samples collected randomly all proved to be negative by

Finally, to determine whether the particles described were related to those found by the American workers, an anti-MS-1 serum was mixed with faecal suspensions from patient J. McG. and from patient E. H. (a Castle Vale case). Agglutination resulted, suggesting some serological relationship with MS-1 virus (fig. 5).

TABLE

Homologous and heterologous reactions between faeces and sera from patients in four distinct incidents of infectious hepatitis, observed by immune electronmicroscopy

\begin{tabular}{l|cccc}
\hline \multirow{1}{*}{ Faeces } & \multicolumn{4}{|c}{ Serum } \\
\cline { 2 - 5 } & J. McG. & Castle Vale & Inverness & Family \\
\hline J. McG. & $+*$ & - & + & + \\
Castle Vale & + & $+*$ & NT & + \\
Inverness & + & NT & + & + \\
Family & + & + & - & + \\
\hline
\end{tabular}

$+=$ Positive result with indicated human serum; $-=$ negative result with indicated human serum; $*=$ positive result with anti-MS-1 serum; NT $=$ not tested.

The cross-reactions of the four groups are shown in the table. It should, however, be remembered that IEM may fail to show agglutination if the proportion of antiserum to antigen is not optimal.

\section{Caesium-chloride density-gradient centrifugation}

IEM is not the most sensitive method for detecting virus; even in the absence of agglutinated particles, infectivity may be present in the faeces of hepatitis-A patients (Krugman et al., 1959; Dienstag et al., 1975).

In the course of characterisation studies on hepatitis-A-associated particles, caesium-chloride density gradients were used to determine buoyant density. However, these also proved to be a sensitive method for detecting virus (figs. $6 a$ and $6 b$ ). Particles consistently banded in a zone of buoyant density 1.34 and could be seen by direct microscopy. Initially, all fractions were examined to determine in which fraction virus could be expected.

In samples containing only a few particles, those that were present were concentrated in one or two gradient fractions and could be more easily seen. For this reason, small fraction volumes were an advantage, because larger ones tended to reduce the concentration of particles in each fraction. The particles seen in fig. 7 (from a contact) appear to be clumped, but their spacing is not consistent with agglutination by antibody. Particles from fractions that were 
found to be positive could be agglutinated with convalescent serum after dialysis against distilled water (fig. 8).

This method was also used to detect particles in samples collected up to 16 days after the onset of illness. Our findings thus corroborate those of Ward et al. (1958) and Krugman et al. (1959), who demonstrated infectivity in stools up to 25 days after infection, although they could not detect particles by electronmicroscopy.

Faecal samples from two infectious-hepatitis patients who had been shown to be excreting particles during their illness were examined by caesium-chloride density-gradient centrifugation 3 months later and in neither could particles still be detected.

\section{Comparison of hepatitis-A-associated particles with small spherical phage particles and echoviruses}

There have been suggestions that particles found in hepatitis A could, in fact, be small, tailless bacteriophages. The situation is complicated by the findings of Almeida, Gay and Wreghitt (1974) that antibodies to several faecal antigens appear during the course of hepatitis-A infection.

In several of the samples we examined, tailed phages were identified but always at a different buoyant density from that of hepatitis-A-associated particles. Also, these phages were not agglutinated by any serum used in this study. Work is in progress to differentiate hepatitis-A particles from phages; here we include electronmicrographs of three of the small phages, $\mathrm{Q} \beta, \mathrm{R} 17$ and $\Phi \mathrm{X} 174$ (figs. $9 a, 9 b$ and $9 c$ ). These show the marked difference in morphology of the phage and hepatitis-A particles and also the difference in size-hepatitis-A-associated particles have a peak size at 23-24 nm and phages at $25-27 \mathrm{~nm}$.

Because of the possibility that the particles found might be of a known enterovirus they were compared with Echovirus. Six faecal suspensions from which Echovirus, type 19, had been isolated in tissue culture were put through the procedure of caesium-chloride density-gradient centrifugation. This virus also bands at density 1.34 and its size $(25-26 \mathrm{~nm})$ is similar to that of hepatitis-A particles. However, whilst Echovirus recovered from gradients caused cytopathic effects in Hep-2 cells, hepatitis-A-associated particles did not.

\section{DisCUSSION}

We report the presence of particles of 23-24 nm, buoyant density 1.34 in naturally occurring cases of infectious hepatitis. This observation contrasts with those of Feinstone et al. (1973) and Provost et al. (1975), who found 27-nm particles associated with hepatitis A. However, Thornton, Zuckerman and Almeida (1975) have recently described particles of variable diameter in faeces from a chimpanzee infected with MS-1 agent; their particles ranged in size from 24 to $29 \mathrm{~nm}$. The apparent differences in size and buoyant density of particles associated with infectious hepatitis have yet to be reconciled. 
FAECAL VIRUS PARTICLES IN HEPATITIS A

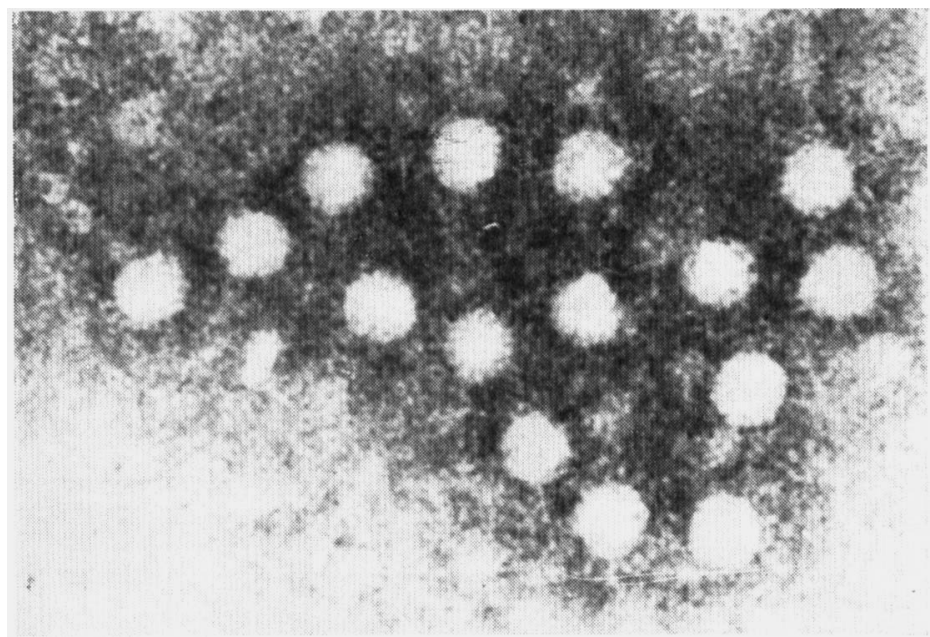

FIG. 1a.-Faecal particles from patient J. McG. agglutinated with homologous serum. $\times 296000$. Phosphotungstate (KPT)

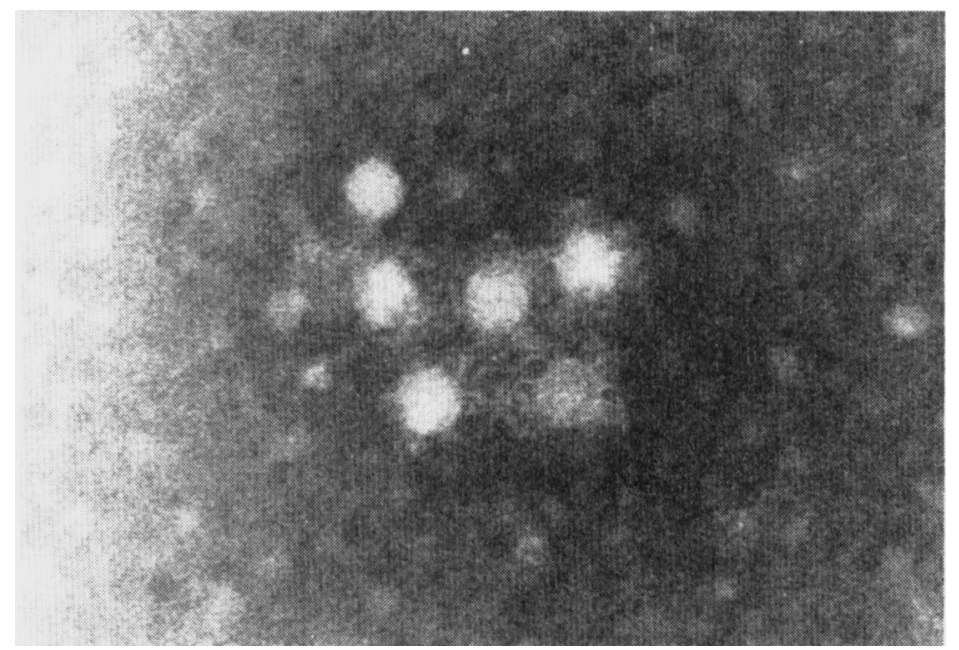

FIG. 1b.-Faecal particles from patient J. McG. agglutinated with convalescent serum of patient R. L. $\times 29600$. KPT 


\section{FAeCAL VIRUS PARTICLES IN HePATITIS A}
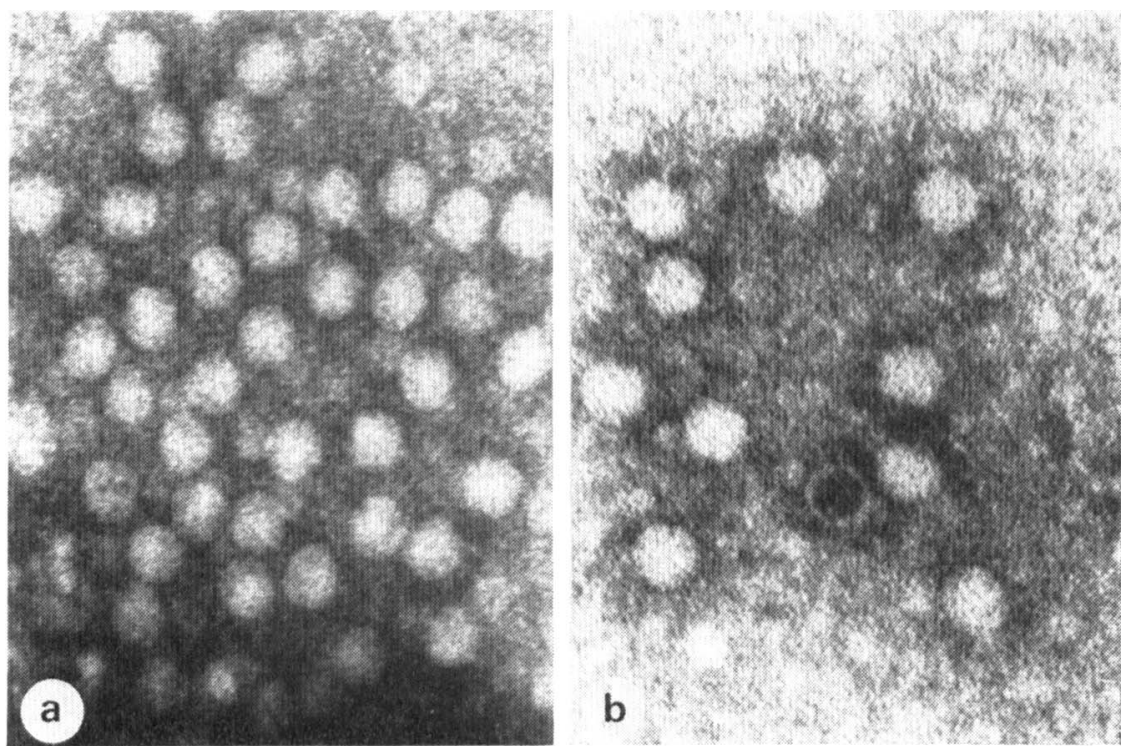

Figs. $2 a$ and $2 b$._-Particles from patients in the Castle Vale outbreak agglutinated by a convalescent serum from the same outbreak. $\times 296000$. KPT

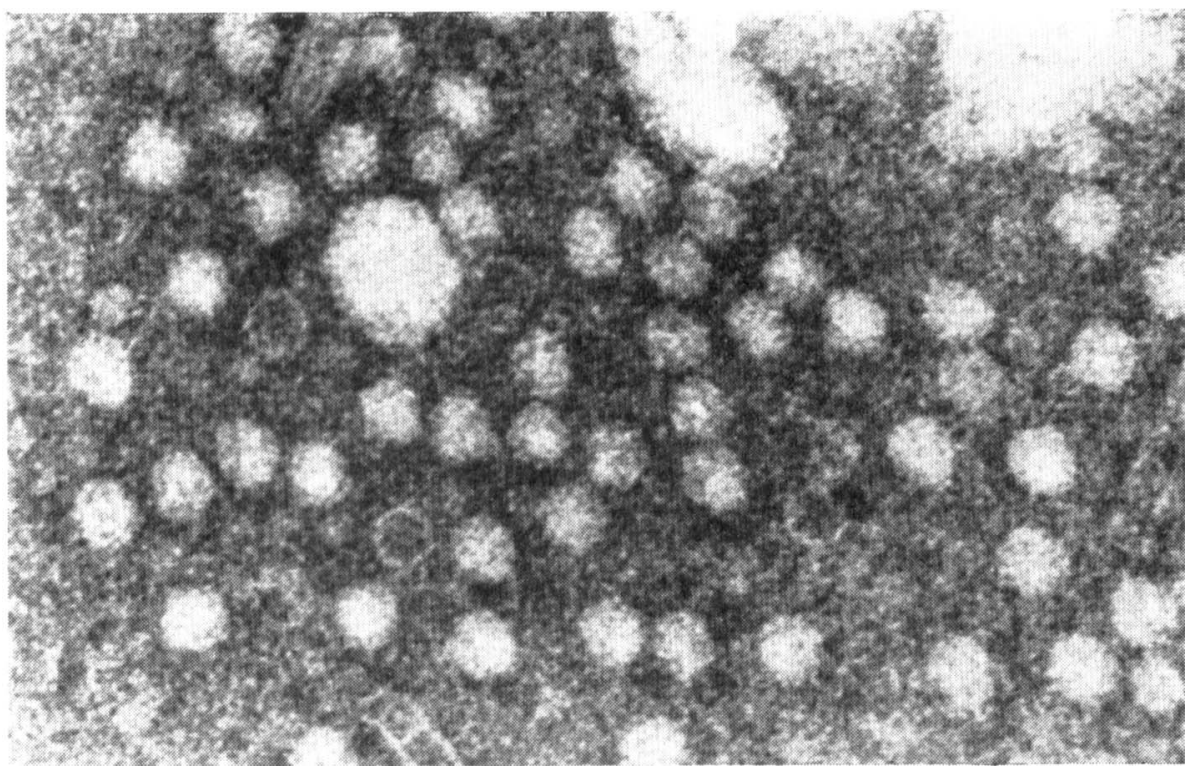

Fig. 3. - Particles from contact L.H. agglutinated by her sister's convalescent serum. $\times 296000$. KPT 
FAECAL VIRUS PARTICLES IN HEPATITIS A
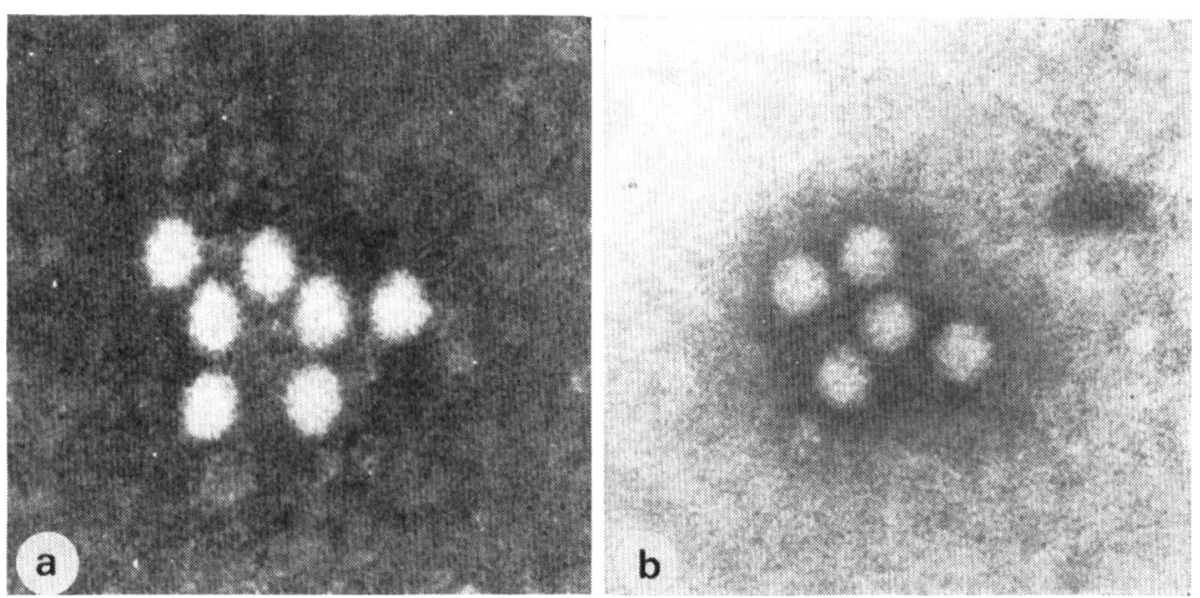

FIGS. $4 a$ and $4 b$.-Particles from patients in Inverness agglutinated with a convalescent serum from the same incident. (Fig. $4 a$ from a case in 1974, Fig. $4 b$ from a case in 1975) $\times 296000$. KPT

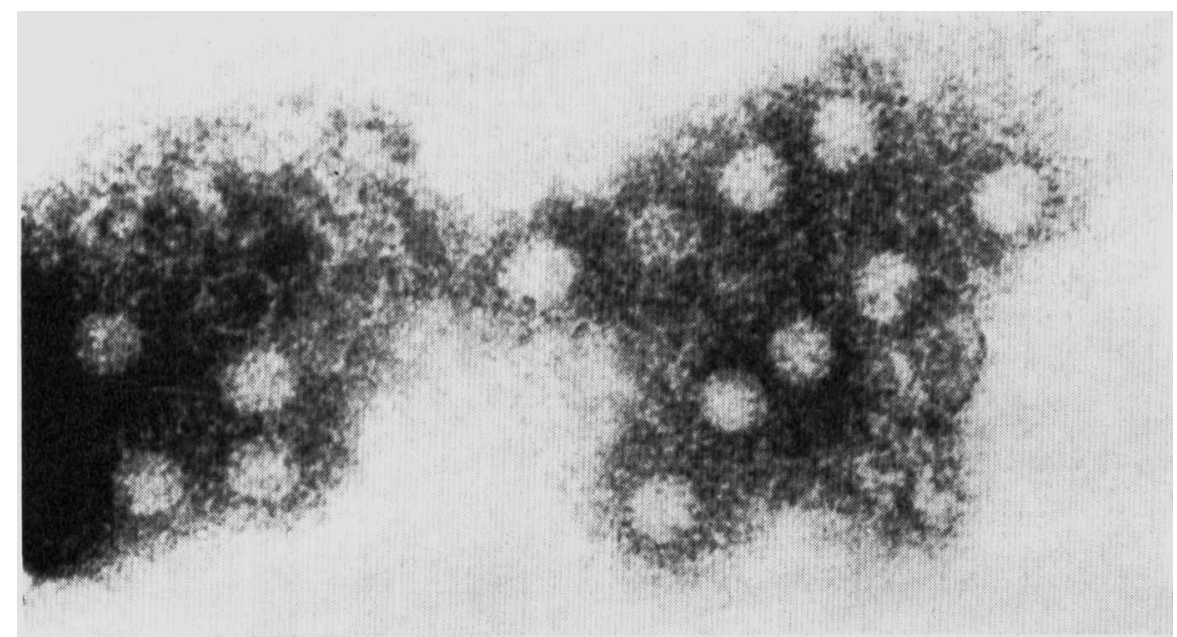

FIG. 5.-Particles from patient J. McG. agglutinated with anti-MS-1 serum. $\times 296000$. KPT 
FAeCAL VIRUS PARTICLES IN HEPATITIS A
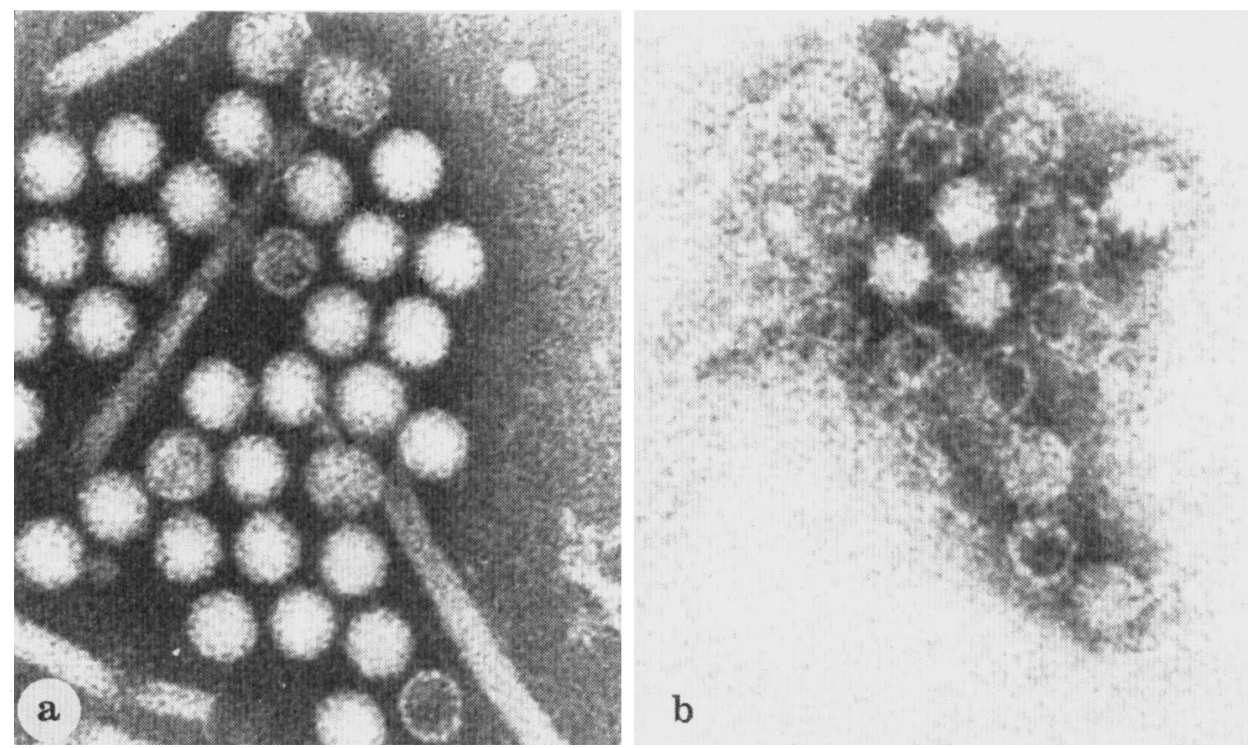

FIGS. $6 a$ and $6 b$.- Particles of density 1.34 from a caesium chloride density gradient. $\times 296000$. KPT

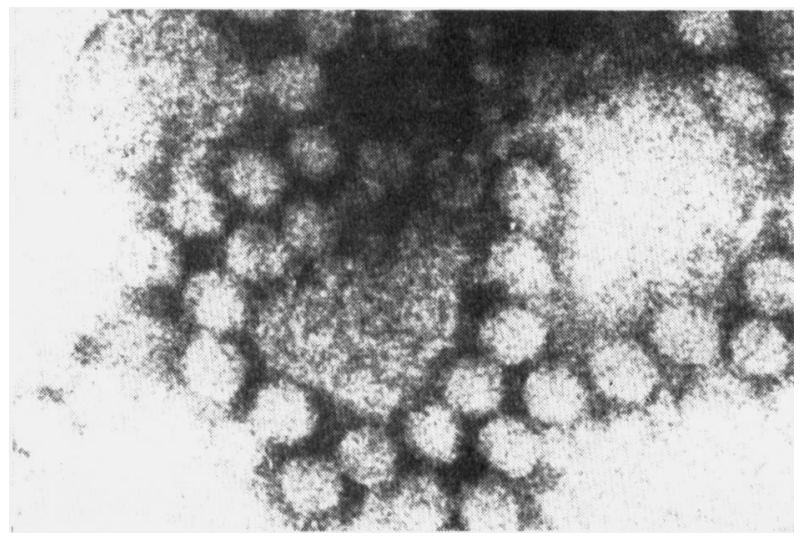

FIG. 7.-Particles from a contact (density $1 \cdot 34$ in a caesium-chloride density gradient). $\times 296000$. KPT 
FAfCAl Virus Particles in hePatitis A

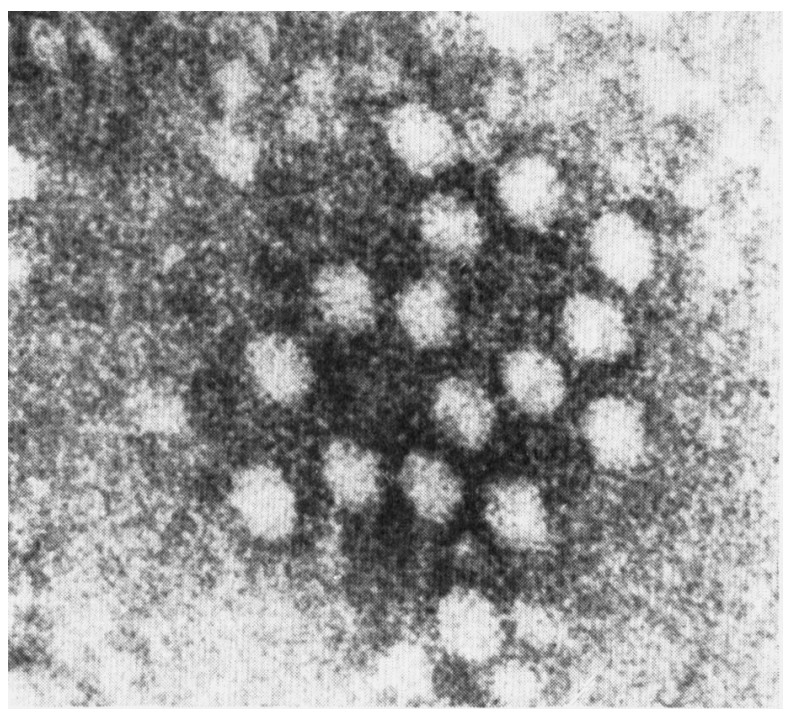

Fig. 8.--Particles from dialysed fractions agglutinated with convalescent serum. $\times 296000 . \quad$ KPT
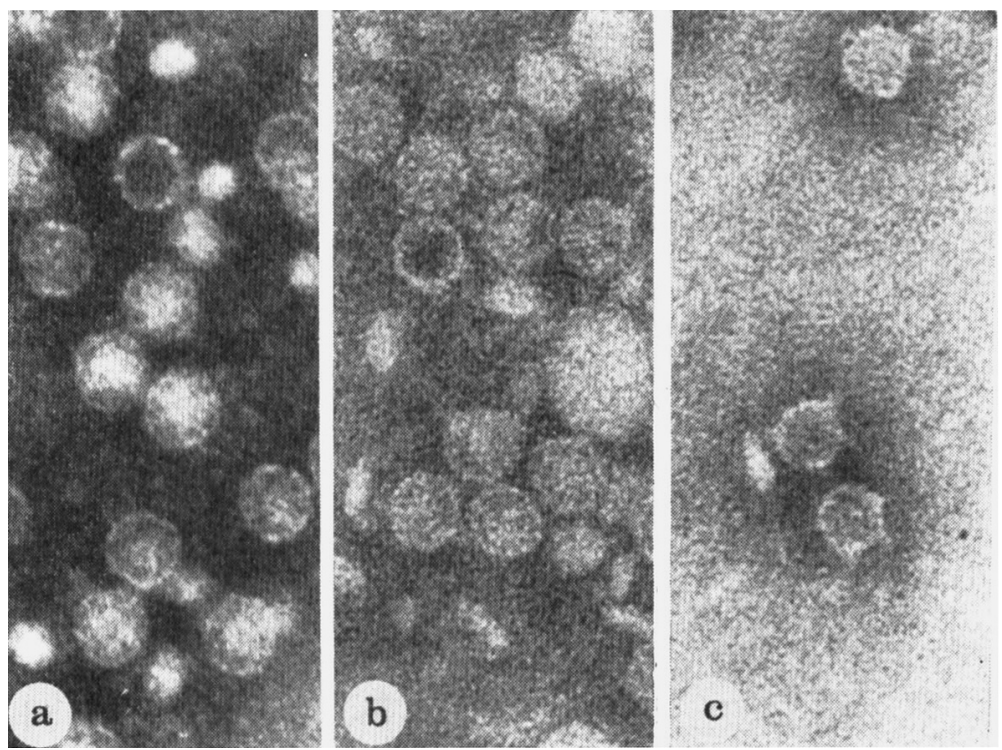

FIGs. $9 a, 9 b$ and $9 c$.-Negatively stained phages $\mathrm{Q} \beta, \mathrm{R} 17$, and $\Phi \mathrm{X} 174$, respectively. $\times 296000$. KPT 
Both Provost et al. (1973) and Feinstone et al. (1974) claim a serological relationship of their particles with the MS-1 agent. The particles described here were also agglutinated by an anti-MS-1 serum. However, the significance of this is uncertain, because some non-specificity of reaction, introduced during passage of the antigen, might account for the cross reactions.

It was difficult to obtain samples in the earliest stage of the infection when there is maximum faecal shedding of virus (Dienstag et al., 1975). Caesiumchloride density-gradient centrifugation was found to be useful in detecting small numbers of particles, especially after jaundice had appeared. Virus was found in several contacts by this method.

There is a need for the collection of serial blood samples from contacts. This would allow serum transaminase levels to be monitored-the ideal way of detecting subclinical hepatitis - and also provide paired sera for studies of seroconversion. In practice it has proved very difficult to obtain such samples.

We do not consider hepatitis-A-associated particles to be phages, because their size and morphology are different from those of several of the known small, spherical phages. Work is in progress to raise antisera against known phages so that these can be removed from faecal suspensions by affinity chromatography. This may help to clarify the role of the particles we have described in infective hepatitis.

\section{SUMMARY}

Forty-one faecal samples from infectious-hepatitis patients and their contacts were investigated for the presence of hepatitis-A-associated viral particles. Of these, 16 gave a positive result by immune electronmicroscopy or caesium-chloride density-gradient centrifugation. The latter method proved invaluable in detecting small numbers of virus particles. The particles found had a buoyant density of 1.34-1.35 and a size range of 21-28 nm. Epidemiological evidence suggested that they might be the causative agent of hepatitis A.

We gratefully acknowledge the help of Mrs H. Davies, who developed and printed the electronmicrographs. We also wish to thank Dr T. H. Flewett for advice and guidance and Dr June Almeida for confirming the particle size. One of us (S. J. S.) is supported by a grant from the Medical Research Council.

\section{REFERENCES}

Almeida, J. D., Gay, F. W. AND Wreghitt, G. 1974. Pitfalls in the study of hepatitis A. Lancet, $2,748$.

Bradley, D. W., Hornbeck, C. L., Gravelle, C. R., Cook, E. H. and Maynard, J. E. 1975. CsCl banding of hepatitis A associated virus-like particles. J. infect. Dis., 131, 304.

Dienstag, J. L., Feinstone, S. M., Kapikian, A. Z. And Purcell, R. H. 1975. Faecal shedding of hepatitis-A antigen. Lancet, $1,765$.

Feinstone, S. M., Kapikian, A. Z. And Purcell, R. H. 1973. Hepatitis A: detection by immune electron microscopy of a virus-like antigen associated with acute illness. Science, N.Y., 182, 1026.

Feinstone, S. M., Kapikian, A. Z., Gerin, J. L. ANd Purcell, R. H. 1974. Buoyant density of the hepatitis-A virus-like particles in cesium chloride. J. Virol., 13, 1412. 
Gravelle, C. R., Hornbeck, C. L., Maynard, J. E., Schable, C. A., Cooke, E. H. and BraDLEY, D. W. 1975. Hepatitis A: report of a common-source outbreak with recovery of a possible etiologic agent. II. Laboratory studies. J. infect. Dis., 131, 167.

Krugman, S., Ward, R., Giles, J. P., Bodansky, O. ANd Jacobs, A. M. 1959. Infectious hepatitis: detection of virus during the incubation period and in clinically inapparent infection. New Engl. J. Med., 261, 729.

Leger, R. T., Boyer, K. M., Pattison, C. P. and Maynard, J. E. 1975. Hepatitis A: report of a common-source outbreak with recovery of a possible etiologic agent. I. Epidemiologic studies. J. infect. Dis., 131, 163.

Provost, P. J., Ittensohn, O. L., Villarejos, V. M., Arguedas, J. A. and Hilleman, M. R. 1973. Etiologic relationship of marmoset-propagated CR326 hepatitis A virus to hepatitis in man. Proc. Soc. exp. Biol. Med., 142, 1257.

Provost, P. J., Wolanski, B. S., Miller, W. J., ItTensohn, O. L., McAleer, W. J. AND Hilleman, M. R. 1975. Physical, chemical and morphological dimensions of human hepatitis A virus strain CR326 (38578). Proc. Soc. exp. Biol. Med., 148, 532.

Thornton, A., Zuckerman, A. J. AND AlmeIDA, J. D. 1975. Chimpanzee model hepatitis-A virus. Lancet, 2, 226.

Ward, R., Krugman, S., Giles, J. P., Jacobs, A. M. AND Bodansky, O. 1958. Infectious hepatitis: Studies of its natural history and prevention. New Engl. J. Med., 258, 407. 